\title{
Eating Habits and Lifestyle Changes Among Turkish Population During Covid-19 Pandemic Period
}

\author{
Sibel Karakayaa, ${ }^{1, a, *}$ Merve Eda Eker ${ }^{1, b}$, Sedef Nehir El ${ }^{1, \mathrm{c}}$, Beste Özsezen ${ }^{2, d}$ \\ ${ }^{I}$ Department of Food Engineering, Faculty of Engineering, Ege University, 35100 Izmir, Turkey \\ ${ }^{2}$ Department of Pediatric Pulmonology, Faculty of Medicine, Hacettepe University,06800 Ankara, Turkey
}

${ }^{*}$ Corresponding author

\section{A R T I C L E IN F O A B S T R A C T}

Research Article

This study aimed to investigate the impact of the Covid-19 pandemic on eating habits, and lifestyles including sleeping and smoking habits, and physical activity of the Turkish population aged $>15$ years using a web-survey. The survey was conducted from the $5^{\text {th }}$ of August to the $4^{\text {th }}$ of October 2020 by using an online platform and disseminated through institutional and private social networks (Facebook and WhatsApp) and institutional mailing lists. The questionnaire consisted of demographic information, anthropometric data, changes in dietary habits, and changes in lifestyle habits. The total number of participants was 1020 in the study and $71.1 \%$ of them are female, and $80 \%$ of the participants were in the $20-59$ age range. More than half of the participants $(67.42 \%)$ declared that their eating habits and lifestyles changed during the Covid-19 pandemic. Most of the participants $(63 \%)$ declared that there is no special food that can improve their immunity against

Keywords:

Covid-19

Physical activity

Food purchase facility

Sleep hours

Smoking habit

the Covid-19. Contrary to them, most of those who added certain foods to their diets or increased the consumption of certain foods to improve the immunity (39.8\%), declared that they got that information from social media such as Twitter, Facebook, and WhatsApp. In particular smoking habits did not change and sleep hours increased during the Covid-19 period. Concerning physical activity, no significant difference was found between the percentage of people before and during the Covid-19 period.

\section{Introduction}

China- WHO Country Office announced that some pneumonia cases of unknown origin showed up on 31 st December 2019 in Wuhan city of Hubei province of China and afterward, it was described in January the 5th, 2020 as a coronavirus which has not been diagnosed on the human body. Afterward, the Turkish Ministry of Health declared the first Covid-19 case in Turkey on March 11, 2020. After this first case, education was suspended in primary, secondary, and high schools and universities on March 12, 2020. Then the activities of entertainment venues were suspended on March 15, 2020 (Budak and Korkmaz, 2020). After that, many precautions such as restrictions on travel and transportation between cities and lockdown on weekends were implemented. Finally, all confinement measures were suspended on June 15, 2020. Due to various confinement measures imposed between 11 March and 15 June 2020, changes in the eating habits and lifestyle of the society would be inevitable.
During the Covid-19 pandemic, many factors may have influenced the food choice and food availability. These factors include impaired food accessibility during confinements, job losses, reduced incomes, and uncertainties about the future (Scarmozzino and Visioli, 2020). Physical distancing and self-isolation may influence eating habits and everyday behaviors. In addition, boredom resulted from the interruption of everyday life (work routine, etc.) may cause an increase in energy intake, consumption of comfort foods rich in sugar, junk foods, snacks high in fats, sugars, and salt. Moreover, dysfunctional eating behaviors may increase due to selfisolation makes people to be more prone to look for reward and gratification physiologically associated with food consumption and accordingly overeating (Di Renzo et al., 2020a). Contrary to these types of changes in eating habits, some people may change eating habits in a positive manner due to the existing knowledge on the relation between diet and mood or health benefits. Those people may incorporate 
healthful foods containing bioactive compounds including polyphenols, vitamins, antioxidants, and monounsaturated fatty acids in their diets during this period. Moreover, lifestyle changes including increased risk of sedentary behaviors, modification of sleeping, and smoking habits due to confinement measures may have occurred during this period.

In the light of the above reasons, the aim of this study is to explore and analyze the changes in eating habits, and the lifestyle including sleeping and smoking habits, and physical activity of the Turkish population during lockdown and confinement period using a web-survey.

\section{Materials and Methods}

The survey was conducted from the $5^{\text {th }}$ of August to the $4^{\text {th }}$ of October 2020 among the Turkish population, by using an online platform that can be accessed from any device with an internet connection. The survey was disseminated through institutional and private social networks (Facebook and WhatsApp) and institutional mailing list. This study reports the findings obtained for the 1020 participants to a national survey on lifestyle and dietary habits changes during confinements and Covid-19 period from March 12, 2020, to June 1, 2020. The questionnaire comprised inquired demographic information (age, gender, place of residence, current employment), anthropometric data (reported weight and height), changes in eating habits during confinements and the Covid-19 pandemic period, and lifestyle habits information (grocery shopping, smoking, sleep quality and physical activity). The full version of the questionnaire is available as a supplement. During the informed consent process, survey participants were assured all data would be used only for research purposes. All participants were fully informed about the aim of the study. Participants were not permitted to provide their names or contact information. In addition, participants were able to stop their participation and leave the questionnaire at any stage before the submission process. Responses were saved by clicking on the provided "submit" button. Although the total number of participants included in the study was 985 because of validated data, the results were evaluated separately for each question, and the frequency of the answers were calculated over the total number of participants who answered the question. The anonymous nature of the websurvey does not allow tracing in any way personal data. Therefore, the present web-survey study does not require approval by the Ethics Committee.

\section{Statistical Analysis}

Statistical analysis was performed using SPSS V27, 2020 (IBM, Chicago, IL, USA). The normal distribution of variables was examined by using visual (histograms, probability plots) and analytical methods (Skewness, kurtosis, Kolmogorov Simirnov, Shapiro Wilk's test and variation coefficient). Data were given as numbers and percentages for categorical variables and mean \pm SD for continuous variables. The results for each question McNemar Bowker analysis were used to investigate the difference between categorical variables pre and during the Covid-19 pandemic.

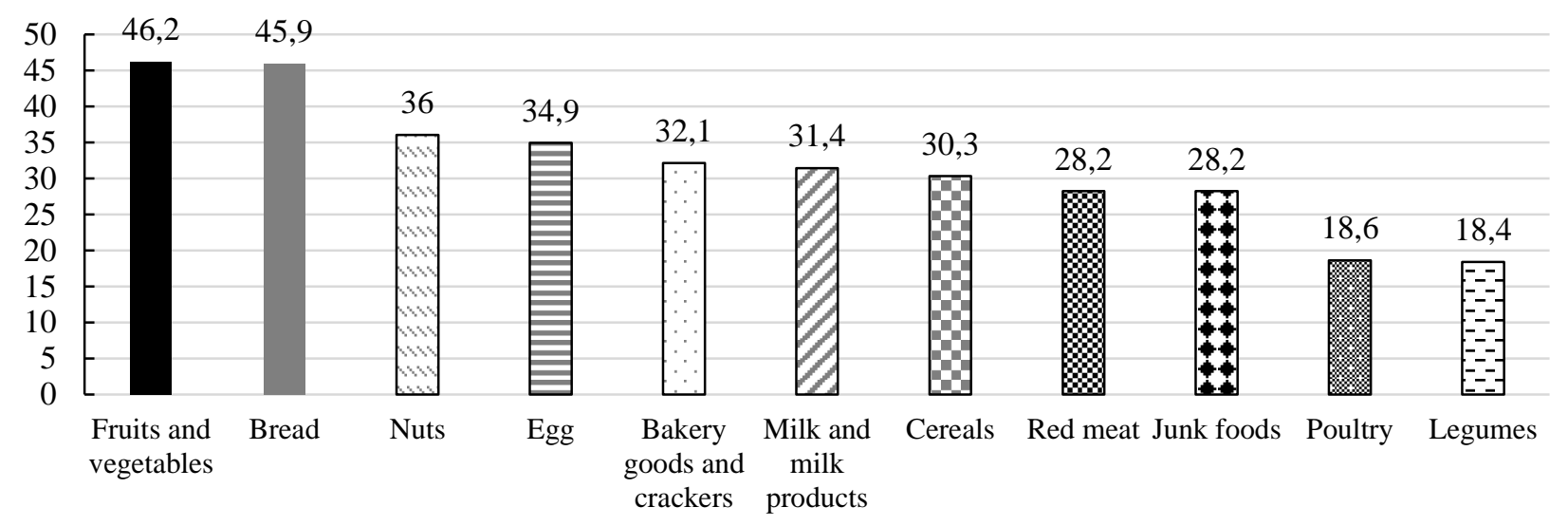

Figure 1. Increased consumption of foods during the Covid-19 pandemic (\%)

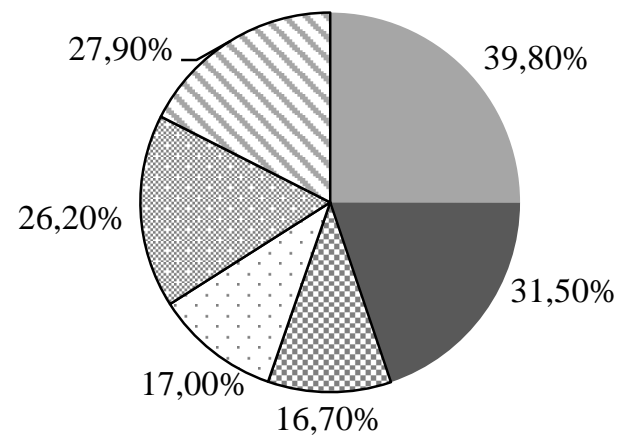

- Social media (twitter, instagram,

whatsapp, etc.)

- Written and visual media (newspaper, tv, etc.)

圆Friends, neighbours, etc.

$\square$ From an infectious disease specialist

Scientific articles

๑Others

Figure 2. Sources of information that participants get (\%) 


\section{Results and Discussion}

The web-survey on the changes in dietary habits of the Turkish people during the Covid-19 outbreak was launched on the $5^{\text {th }}$ August 2020 and concluded on the $4^{\text {th }}$ of October 2020. A total of 1020 participants completed the questionnaire, and after data validation, 985 respondents were included in the study. The distribution of the participants according to the cities they lived in was $38.99 \%$ from İzmir, $13.98 \%$ from Istanbul, $8.9 \%$ from Ankara, and $38.11 \%$ from other provinces. Table 1 . shows the general characteristics of the participants. Overall, $71.1 \%$ of the participants were female and $80 \%$ of the participants were between the ages of 20-59. Most of the participants have a bachelor's degree (70.7\%). According to the working conditions, $22.2 \%$ of the participants went to the workplace as usual and $8.9 \%$ worked at home. Forty percent of the participants were students, $16.6 \%$ were retired, $7.1 \%$ were not working, $2.2 \%$ were unemployed, and $2.9 \%$ had suspended work.

Table 2. shows the anthropometric data of the participants. Body Mass Index (BMI) of females were in the range of normal (18.50-24.99), but males were in the overweight category (25.00-29.99) according to BMI.

Six hundred twenty-seven participants $(67.4 \%)$ declared that their eating habits and lifestyles changed during Covid-19 pandemic confinement and approximately $18 \%$ of them had changes in favor of unhealthy foods such as cake, bakery goods, sausage, fast foods, snacks, and desserts. The results also showed that $29.6 \%$ of the participants made their own bread at home during this period. Especially fruits and vegetables, and bread consumption increased during confinement (Figure 1). This was followed by nuts, eggs, bakery goods, and crackers, milk and milk products, cereals, red meat, junk foods, legumes, and poultry. Among the beverages, the most consumed one was coffee, $34.7 \%$ of the participants declared that their coffee consumption increased during containment. Other beverages whose consumption increased during this period were black tea (33.8\%), carbonated beverages $(16.3 \%)$, herbal teas $(11.8 \%)$, alcoholic beverages (11.8\%), and green tea (11.2\%).

In our study the number of meals changed in 534 participants $(57.4 \%$ ) during the Covid-19 pandemic. These changes were the increase in snack foods consumption (25.8\%), skipping main meals $(21.8 \%)$, and adding one or more meals in a daily diet (9.8\%). In $42.8 \%$ of the participants the number of daily meals did not change.

Most of the participants $(63 \%)$ specified that neither they increased the consumption of any foods nor added any foods into their diet. Whereas other participants stated that they added or increased the consumption of some foods including fruits and vegetables, onion, garlic, radish, ginger, turmeric, sumac, spices, honey, kefir, probiotics, yogurt, some herbal teas, propolis, vinegar, and nuts thinking that these foods will improve their immune system to be protected from Covid-19. Although we did not specifically ask whether they used dietary supplements to improve their immune system, a small number of participants (8 people) declared that they take vitamin and mineral supplements, and herbal supplements during the Covid-19 pandemic.

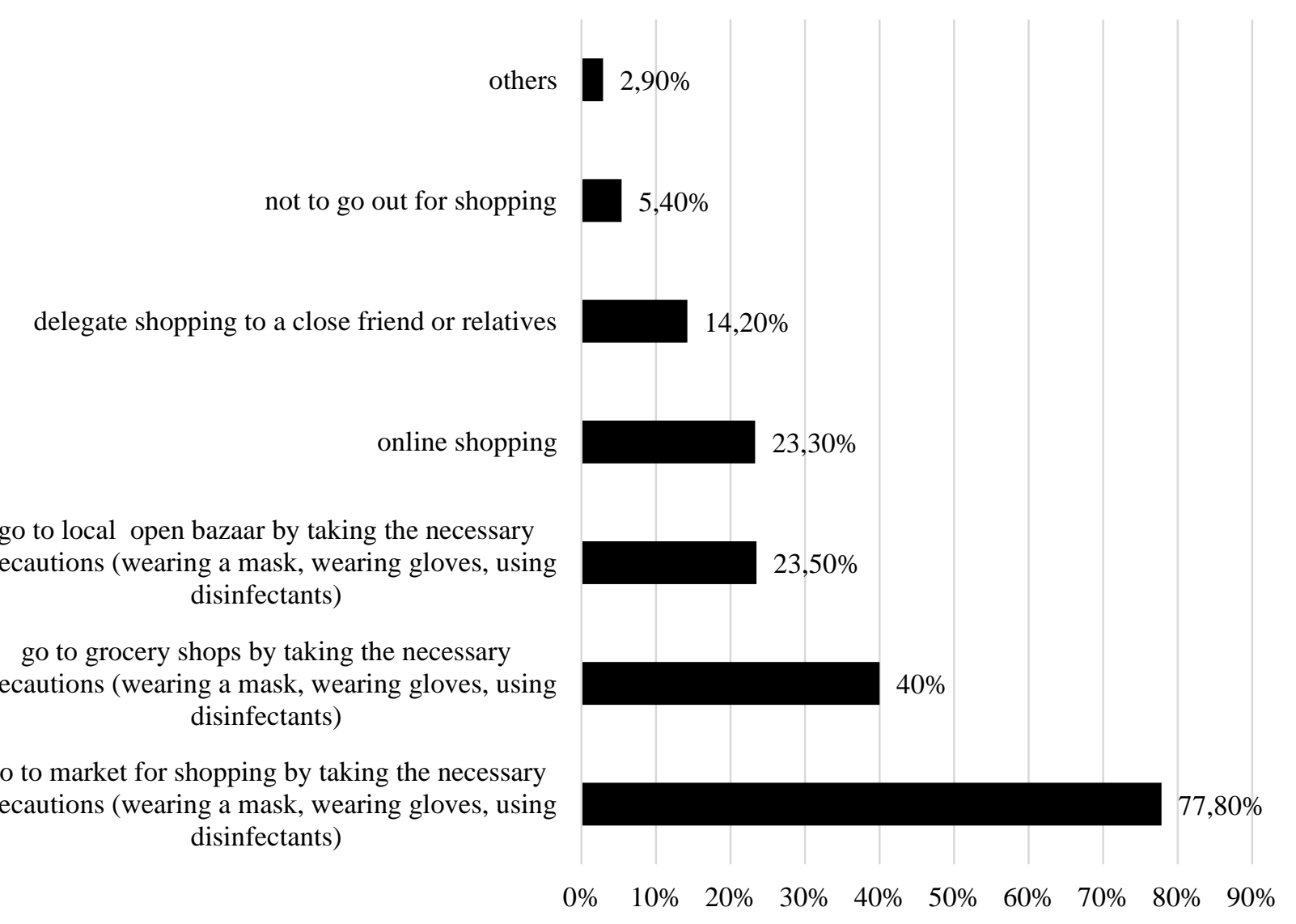

Figure 3. Shopping facilities during the Covid-19 pandemic (\%) 


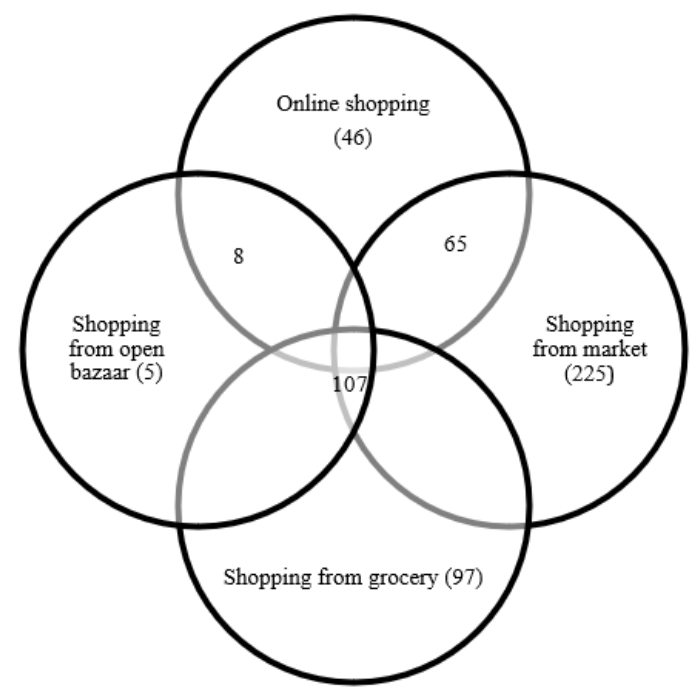

Figure 4. Venn diagram of mostly preferred shopping facilities

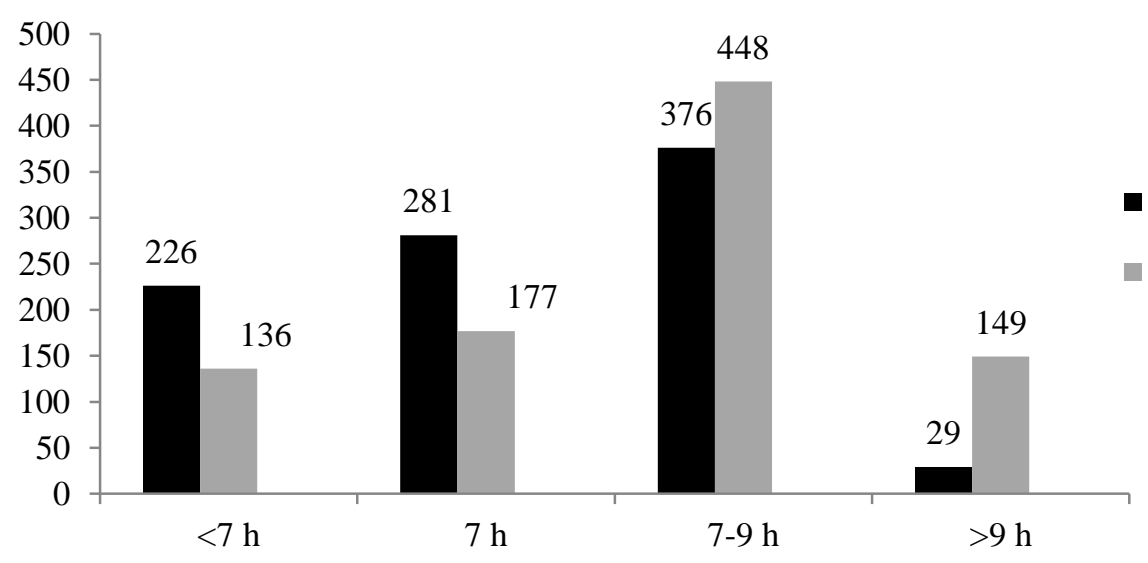

Sleep hours (before Covid-19)

Sleep hours (after Covid-19)

Figure 5. Changes in the sleep hours of the participants before and after Covid-19 pandemic (results were given as the number of the participants).

Among 359 participants (38.6\%) who added certain foods to their diets or increased the consumption of certain foods to improve the immune system, 143 of them (38.9\%) declared that they got this information from social media such as Twitter, Facebook, and WhatsApp (Figure 2), followed by printed and visual media (n:113, 31.5\%) and scientific articles (n:94, 26.2\%), respectively. [Figure 2.may be presented here]. Hundred participants (27.9\%) declared they got the information from other sources. Most of them are medical doctors, dentists, food engineers, pharmacists, etc. and they indicated that they have already noticed this information because of their professions in this field. Some of them declared that they were informed by the professions like a dietitian, an osteopath, a medical doctor, a pharmacist. A few of them stated that they got this information from their parents, family members, and books on healthy nutrition.

Participants were asked to choose one or more of the shopping facilities including online shopping, shopping from the market, shopping from groceries, shopping from the open bazaar, delegating shopping to a close friend or relatives, and not going out for shopping. Various food purchase facilities were detected and most of the participants indicated that they continue to go to the market and/or local open bazaar for food purchasing by taking the necessary precautions.
Online shopping was an alternative option, and 23.3\% of respondents preferred online shopping, as expected. Since the participants can choose more than one alternative, the Venn diagram is used to see these alternatives (Figure 4). A total of 840 participants (92\%) preferred to purchase their foods from the market, groceries, open bazaar, and online platform. Among them, 107 people $(12.7 \%)$ purchased their foods both from the market, groceries, and open bazaar. The number of people purchased their foods both from online platform and market was $65(7.7 \%)$.

In terms of sleep hours, $41.2 \%$ of the participants slept 7-9 hours/day, $30.8 \%$ slept 7 hours/day, $24.8 \%$ slept less than 7 hours/day and 3.2\% slept more than 9 hours/day before the Covid-19 pandemic. However, their sleep hours have changed (McNemar Bowker value=197.930, $\mathrm{P}<0.001$ ) during confinement measures (Figure 5).

Smoking habits did not change during confinement measures (odds ratio for non-smokers/smokers: 350.766). During this period, only 6 smokers quit smoking, 5 nonsmokers started smoking, and 4 smokers increased the number of cigarettes per day in this period. These results showed that the participants had no fear of the increased risk of respiratory distress and mortality from Covid-19 in smokers. 
Table 1. General Characteristics of The Participants $(n=985)$

\begin{tabular}{|c|c|c|c|}
\hline \multicolumn{2}{|c|}{ Characteristics } & Participants (number) & Percentage $(\%)$ \\
\hline \multirow{3}{*}{ Gender } & Female & 700 & 71.1 \\
\hline & Male & 285 & 28.9 \\
\hline & $15-19$ & 95 & 9.60 \\
\hline \multirow{3}{*}{ Age (years) } & $20-39$ & 491 & 49.9 \\
\hline & $40-59$ & 297 & 30.2 \\
\hline & $>60$ & 102 & 10.4 \\
\hline \multirow{4}{*}{ Education } & Secondary school & 11 & 1.10 \\
\hline & High school & 84 & 8.50 \\
\hline & Bachelor's degree & 696 & 70.7 \\
\hline & Master/doctorate degree & 194 & 19.7 \\
\hline \multirow{7}{*}{ Current employment } & Not working & 70 & 7.10 \\
\hline & Unemployed & 22 & 2.20 \\
\hline & Retired & 164 & 16.6 \\
\hline & Student & 394 & 40.1 \\
\hline & Working at home & 88 & 8.90 \\
\hline & Currently suspended a work & 29 & 2.90 \\
\hline & Go to work as usual & 218 & 22.2 \\
\hline
\end{tabular}

"Data were presented as a number and percentage (n (\%)) for categorical variables

Table 2. Anthropometric Data of The Participants $(n=985)$

\begin{tabular}{l|cc}
\hline \multicolumn{1}{c|}{ Data } & Female & Male \\
\hline Weight $(\mathrm{kg})$ & $63.06 \pm 11.19$ & $81.76 \pm 13.27$ \\
Height $(\mathrm{cm})$ & $164.00 \pm 9.28$ & $178.02 \pm 6.80$ \\
BMI & $23.46 \pm 5.36$ & $25.77 \pm 3.91$ \\
\hline
\end{tabular}

"Data were presented as mean \pm standard deviation. BMI, body mass index

The physical activity frequency among participants before and during COVID-19 pandemic were $38.3 \%$ and $39.1 \%$ respectively and it was not statistically significant $($ McNemar value $=0.166, \mathrm{P}: 0.68)$.

This study showed that during March 12, 2020, and June $1,2020,2.2 \%$ of the participants were unemployed and $22.2 \%$ of them were working in the workplace similar to before the Covid-19 pandemic. Similarly, the percentage of the participants who worked in the working place was $19.1 \%$ in the study of Di Renzo et al. (2020a). However, the percentage of unemployed participants was higher (26.6\%) than we determined. Participants who declared changes in their eating habits and lifestyles were more than half of the participants (67.42\%) during Covid-19 pandemic confinement and approximately $18 \%$ of them had changes in favor of unhealthy foods such as cake, bakery goods, sausage, fast foods, snacks, and desserts. Ammar et al. (2020) reported the effects of Covid-19 home confinement on eating behavior and physical activity. Thirty-five research organizations from Europe, NorthAfrica, Western Asia, and the USA were included in this survey. The results from 1047 participants indicated that food consumption and meal patterns were changed from healthy to unhealthy during confinement. These changes were increased consumption of unhealthy foods such, eating out of control, more snacking between meals, and an overall higher number of main meals. Similarly, more than half of the Italian respondents claimed that they felt a change in their hunger/satiety perception during confinement (Di Renzo et al., 2020b).

Most of the participants stated that their number of daily meals changed during this period. These changes were an increase in snack foods consumption $(25.81 \%)$, skipping main meals $(21.83 \%)$, and adding one or more meals in a daily diet $(9.78 \%)$. Similar to our results Di Renzo et al. (2020b) reported that some of the participants skipped or introduce a break to the main meals $(17.5 \%)$ or introduce the main meal (23.5\%). Scarmozzino and Visioli (2020) and Di Renzo et al. (2020b) reported that the percentage of the participants who stated that they did not modify their meal intake were $49.6 \%$ and $57.8 \%$, respectively. Sidor and Rizymski (2020) indicated that the daily meal intake of $30.3 \%$ of the participants was 3 times per day and $39.3 \%$ of the participants was 4 times per day.

Among the foods whose consumption increased during the Covid-19 period, fruits and vegetables and bread were in the first order. Scarmozzino and Visioli (2020) and Rodríguez-Pérez et al. (2020) reported an increase in fruits and vegetable consumption. However, a Polish study demonstrated that approximately one-third of the participants did not consume fresh fruits and vegetables on a daily basis. Nevertheless, researchers observed that nearly one-third of those surveyed consumed sweets at least every day (Sidor and Rizymski et al., 2020). Similar to our results, Spanish people have been increased their consumption of vegetables, fruits, and other Mediterranean foods, such as olive oil, legumes, etc. during the COVID19 confinement period (Rodríguez-Pérez et al., 2020). The difference among the eating behaviors of the populations might strongly be due to their dietary habits. Especially people living in the Mediterranean region are used to consume fruits and vegetables, legumes, nuts, and fish regularly.

Sleep hours have changed (McNemar Bowker value $=197.930, \mathrm{P}<0.001)$ during confinement measures. Similar studies reported that most of the participants complained about the worsening of sleep quality and increased insomnia symptoms (Gupta et al., 2020; Marelli 
et al., 2021). Huang and Zhao (2020) stated that nearly $1 / 5$ of participants had depressive symptoms and sleep problems during the Covid-19 period.

Smoking habits did not change during confinement measures (odds ratio for non-smokers/smokers: 350.766) indicating that the participants had no fear of the increased risk of respiratory distress and mortality from the Covid-19 in smokers. In contrast, $3.3 \%$ of Italian smokers quit smoking during this period, and the number of those who smoked more than 10 cigarettes per day decreased by $0.5 \%$ (Di Renzo et al., 2020b). However, Sidor and Rzymski (2020) observed that $45 \%$ of smokers increased their smoking frequency and $40 \%$ of smokers did not change their smoking routine during the confinement period.

We did not observe any changes in the physical activity intensity of the participants during the Covid-19 period $(\mathrm{McNemar}$ value $=0.166, \mathrm{P}>0.005)$. Although Di Renzo et al. (2020b) found no changes in the physical activity habits of Italian people similar to our findings and the percentage of the participants who declared they did not perform physical activity was low $(37.4 \%)$ in comparison to the percentage that we observed in the study. In addition, it should not be ignored that the Covid-19 confinement period prevents people from going out, and this indirectly causes a decrease in physical activity. This situation was questioned in the study of Ammar et al. (2020), Pellegrini et al. (2020) and the adverse effect of the confinement on the physical activity behavior was reported. In addition to the decrease in the number of people doing physical activity, it was found that the duration of physical activity decreased by $33.5 \%$ in those who continued to perform physical activity during the confinement period (Ammar et al., 2020). Another finding reported in the study was that the increase in the daily sitting time by $28 \%$ (Ammar et al., 2020).

In conclusion, the present study indicates that during confinements and the Covid-19 period from March 12, 2020, to June 1, 2020, a significant percentage of individuals changed their dietary habits and lifestyles. People consumed more fruit, vegetable, and bread during this period than in the pre-pandemic. Considering that people's attitude towards learning about the relationship between food choices and improving immunity, it was found that social media such as Twitter, Facebook, and WhatsApp were the driving force. In particular smoking habits did not change and sleep hours increased during Covid-19. Concerning physical activity, there was no significant difference in the percentage of people before and during the Covid-19 period.

Since misleading information on nutrition have been continuing to increase nowadays, there is a need to convey public messages about healthy eating and healthy food choices throughout life and during uncertain times such as the pandemic. Therefore, future studies should focus on tailored information to public on healthy eating patterns, the importance of following healthy eating patterns, and adequate physical activity in such circumstances.

\section{Ethical Approval}

No ethical approval was required as the survey is not permitted to access personal data and all the data analyzed were publicly available.

\section{Funding}

This research did not receive any specific grant from funding agencies in the public, commercial, or not-forprofit sectors.

\section{Conflict of Interest Disclosure}

The authors have not stated any conflicts of interest.

\section{References}

Budak F, Korkmaz Ş. 2020. Covid-19 pandemi sürecine yönelik genel bir değerlendirme: Türkiye örneği. SAYOD, 1: 62-79. doi:10.35375/sayod.738657

Scarmozzino F, Visioli F. 2020. Covid-19 and the subsequent lockdown modified dietary habits of almost half the population in an Italian sample. Foods, 9(5): 675. doi:10.3390/foods9050675

Di Renzo L, Gualtieri P, Cinelli G, Bigioni G, Soldati L, Attinà A, Bianco FF, Caparello G, Camodeca V, Carrano E, Ferraro S, Giannattasio S, Leggeri C, Rampello T, Lo Presti L, Tarsitano MG, De Lorenzo A. 2020a. Psychological aspects and eating habits during covid-19 home confinement: Results of ehlccovid-19 Italian online survey. Nutrients, 12: 1-14. doi:10.3390/nu12072152

Di Renzo L, Gualtieri P, Pivari F, Soldati L, Attinà A, Cinelli G, Leggeri C, Caparello G, Barrea L, Scerbo F, Esposito E, De Lorenzo A. 2020b. Eating habits and lifestyle changes during COVID-19 lockdown: An Italian survey. Journal of Translational Medicine, 18: 1-15. doi: 10.1186/s12967-02002399-5

Ammar A, Brach M, Trabelsi K, Chtourou H, Boukhris O, Masmoudi L, Bouaziz B, Bentlage E, How D, Ahmed M, Müller P, Müller N, Aloui A, Hammouda O, PaineirasDomingos LL, Braakman-Jansen A, Wrede C, Bastoni S, Pernambuco CS, Mataruna L, Taheri M, Irandoust K, Khacharem A, Bragazzi NL, Chamari K, Glenn JM, Bott NT, Gargouri F, Chaari L, Batatia H, Ali GM, Abdelkarim O, Jarraya M, Abed KE, Souissi N, Van Gemert-Pijnen L, Riemann BL, Riemann L, Moalla W, Gómez-Raja J, Epstein M, Sanderman R, Schulz SV, Jerg A, Al-Horani R, Mansi T, Jmail M, Barbosa F, Ferreira-Santos F, Šimunič B, Pišot R, Gaggioli A, Bailey SJ, Steinacker JM, Driss T, Hoekelmann A. 2020. Effects of COVID-19 home confinement on eating behaviour and physical activity: results of the eclb-covid19 international online survey. Nutrients, 12: 1583-1596. doi: $10.3390 /$ nu12061583

Sidor A, Rzymski P. 2020. Dietary choices and habits during COVID-19 lockdown: Experience from Poland. Nutrients, 12(6): 1-13. doi:10.3390/nu12061657

Rodríguez-Pérez C, Molina-Montes E, Verardo V, Artacho R, García-Villanova B, Guerra-Hernández EJ, Ruíz-López MD. 2020. Changes in dietary behaviours during the COVID-19 outbreak confinement in the Spanish COVIDiet study. Nutrients, 12(6): 1-19. doi: 10.3390/nu12061730

Gupta R, Grover S, Basu A, Krishnan V, Tripathi A, Subramanyam A, Nischal A, Hussain A, Mehra A, Ambekar A, Saha G, Mishra KK, Bathla M, Jagiwala M, Manjunatha N, Nebhinani N, Gaur N, Kumar N, Dalal PK, Kumar P, Midha PK, Daga R, Tikka SK, Praharaj SK, Goyal SK, Kanchan S, Sarkar S, Das S, Sarkhel S, Padhy SK, Sahoo S, Satyanarayana Rao TS, Dubey V, Menon V, Chhabra V, Lahan V, Avasthi A. 2020. Changes in sleep pattern and sleep quality during COVID-19 lockdown. Indian Journal of Psychiatry, 62: 370-378. doi:10.4103/psychiatry.Indian JPsychiatry_523_20

Marelli S, Castelnuovo A, Somma A, Castronovo V, Mombelli S, Bottoni D, Leitner C, Fossati A, Ferini-Strambi L. 2021. Impact of COVID-19 lockdown on sleep quality in university students and administration staff. Journal of Neurology, 268(1): 8-15. doi:10.1007/s00415-020-10056-6 
Huang Y, Zhao N. 2020. Generalized anxiety disorder, depressive symptoms and sleep quality during COVID-19 outbreak in China: a web-based cross-sectional survey. Psychiatry Research, 288: 112954. doi:10.1016/j.psychres.2020.112954
Pellegrini M, Ponzo V, Rosato R, Scumaci E, Goitre I, Benso A, Belcastro S, Crespi C, De Michieli F, Ghigo E, Broglio F, Bo S. 2020. Changes in weight and nutritional habits in adults with obesity during the "lockdown" period caused by the COVID-19 virus emergency. Nutrients, 12(7): 1-11. doi:10.3390/nu12072016 